\title{
FESTAS RELIGIOSAS, SANTUÁRIOS NATURAIS E VETORES DE LUGARES SIMBÓLICOS
}

\author{
Religious Festivals, Nature Shrines and Places of Symbolic Vectors
}

\author{
Prof. Dr. Christian Dennys Monteiro de Oliveira \\ Pós-Graduação em Geografia da Universidade Federal do Ceará \\ Campus do Pici, B1. 911, CEP: 60.445-760 - Fortaleza (CE), Brasil
}

Tel/Fax: (+55 85) 33669855 / 33669864 - cdmo49@yahoo.com.br

\section{aaCaa}

\begin{abstract}
Resumo
O artigo desenvolve uma reflexão sobre a presença de festas religiosas na contemporaneidade, mostrando seus vínculos com os espacos naturais e metropolitanos. O texto corresponde a um ensaio de intenção metodológica e busca identificar, a partir de dois casos regionais representativos - os santuários de N.S da Abadia (Niquelândia-GO) e N. S. das Dores (Juazeiro do Norte-CE) - as forças de consolidação de um lugar simbólico para além da geografia das religiões. Após apresentar os modelos de santuários que a prática do turismo contemporâneo tem organizado neste e em outros centros religiosos brasileiros, o trabalho expõe uma metodologia capaz de operar três forças vetoriais (míticas, políticas e mediáticas). Com o relativo equilibro destas forças, o estudo geográfico das festas populares pode construir indicadores na valorização patrimonial dos lugares. O exemplo que finaliza essa relação aponta a importância de articulação dessas festas na gestão de patrimônios naturais
\end{abstract}

Palavras-chave: Santuários naturais, Vetores, Patrimônio, Festas religiosas.

\begin{abstract}
The paper develops a reflection on the presence of religious parties in the contemporary, showing their links to the natural areas and metros. The text corresponds to a test of methodological intent and seeks to identify, from two regional representative cases - the shrines N. S. de Abadia (Niquelândia-GO) and N. S. das Dores (Juazeiro-CE) - the forces of consolidation of a symbolic place beyond the geography of religions. After presenting the models of shrines that the practice of contemporary tourism has organized this and other religious centers in Brazil, the article presents a methodology capable of operating three vector forces (mythical, political and media). With the relative balance of these forces, the geographical study of festivals can build equity indicators in the valuation of places. The example concludes that this relationship indicates the importance of articulating these parties in the management of natural heritage.
\end{abstract}

Key words: Shrines, Vectors, Heritage, Religious parties.

\section{Resumen}

El trabajo desarrolla una reflexión sobre la presencia de los partidos religiosos en el contemporáneo, que muestra sus vínculos con las áreas naturales y áreas metropolitanas. El texto corresponde a una prueba de la intención metodológica y trata de identificar, a partir de dos casos representativos regionales - los santuarios de N. S da Abadia (Niquelândia-GO) y N. S. das Dores (Juazeiro do Norte-CE) - las fuerzas de la consolidación de un lugar simbólico más allá de la geografía de las religiones. Después de presentar los modelos de los santuarios que la práctica del turismo contemporáneo se ha organizado, en este y otros centros religiosos en Brasil, el artículo presenta una metodología capaz de operar tres vectores de fuerza (mítico, político y mediático). Con el relativo equilibrio de estas fuerzas, el estudio de la geografía de los festivales puede construir indicadores de equidad en la valoración de los sitios. En el ejemplo que cierra esa relación indica la importancia de articular estos festivales en la gestión del patrimonio natural.

Palabras clave: Santuarios naturales, Vectores, Patrimonio, Fiestas religiosas.

\section{aaAaa}

Revista da ANPEGE, v. 7, n. 8, p. 93-106, ago./dez. 2011.

ISSN 1679-768 X @ @ 2003, Associação Nacional de Pesquisa e Pós-Graduação em Geografia. Todos os direitos reservados. 


\section{INTRODUÇÃO}

O presente estudo representa os movimentos interpretativos de um encontro entre investigações que culminaram na disciplina Dinâmica dos Lugares Simbólicos (PPGG/UFC) e a pesquisa interinstitucional "Dimensões Territoriais das Festas populares e do Turismo: Estudo comparativo do Patrimônio imaterial nos estados de Goiás, Ceará e Sergipe" (Edital 07/2008 - Ministério da Cultural/Capes-MEC). Busca, portanto, o envolvimento de estudos sobre os santuários católicos, em franco processo de turistificação (econômica e cultural), com uma das faces patrimoniais das festas populares: sua relação simbólica frente às paisagens naturais.

Para fazermos um tratamento exploratório dessas questões na geografia, é preciso assumir um compromisso inicial (e até radical) com a criatividade científica, em detrimento ao chamado pensamento crítico. Isso porque os parâmetros do desenvolvimento contemporâneo vêm sendo ferozmente corroídos pela incompetência da crítica, pois toda vez que acusamos o "capital" (monstro hegemônico) como responsável pela devastação do planeta, assumimos um discurso simplificador de processos complexos, do qual fazemos parte desde sempre. Simultaneamente isentamos as densas tramas das culturas sociais da primeira escala de responsabilidades, quanto à colaboração direta para o cenário de destruição e crises.

Afinal, não há sistema sem seres sistêmicos; e estes não nascem jamais plenamente articulados às cadeias engenhosas do lucro e da reprodução ampliada. Seja na infầncia das elites ou na senilidade das massas subalternas; tudo o que praticamos contra ou a favor da devastação é incompleto, inconstante e demonstrativo de ensaios e erro. Não se destrói/constrói coisa alguma de uma só vez. Todas as coisas que conhecemos, incluindo a destruição manifestam de fato um longo exercício de aprendizagem.

Não se trata de negar os escandalosos descaminhos do processo de urbanização descompassado de projeto prioritariamente social, marca indelével das grandes cidades brasileiras. Trata-se de afirmar - exatamente pelo convívio de uma sabedoria popular na massa constituinte desse processo - a validação simbólica da vida metropolitana como meio espaço-tempo (como privilegiou Elisee Reclus). A partir dessa validação, pretende-se decodificar aqui uma geograficidade dardeliana, renovada pelos significantes afetivos do espaço metropolitano como mediação exemplar entre a comunicação e a cultura (FERRARA, 2008) de um todo social.

Esse processo aponta permanentemente para importância do reconhecimento de vetores capazes de "motorizar" a valorização do patrimônio constituído (de forma tangível ou intangível) no sistema urbano. E tal apontamento não tem mecanismos intrínsecos de impedir ou barrar a apropriação capitalista; muito mesmo a descaracterização de suas mais "nobres" criações populares. A metrópole simula o processo mais perfeito de antecipação presente do projeto futuro de qualquer cidade. Exatamente para lembrar, na prática, que tais futuros são apenas possíveis na plenitude paradoxal da cidade-espetáculo (SILVA; GALENO: 2004).

Pode-se absorver a vertigem de tal paradoxo nos grandes e incontroláveis eventos que, da forma mais monumental possível, anunciam a prorrogação da crença em um futuro ideal. Projetos globalizados como o Mundial de Futebol da FIFA, os Jogos Olímpicos, a Exposição Mundial de Cultura e Tecnologias, com suas indispensáveis sedes metropolitanas materializam essa prorrogação. Entretanto, nenhum desses eventos consegue esconder, eliminar ou mesmo reduzir a insignificância cotidiana os inúmeros rituais de encontro e celebração do festejar no caos metropolitano, mesmo sem saber o quanto estes tendem a anunciar os novos santuários naturais que se multiplicam no país e no planeta.

É desse "desconhecimento" multiplicador que um tipo fundamental de festa sobrevive como resistência imaginativa (AVENS, 1993): a festa religiosa, marcantemente espetacular, dada sua escala metropolitana. Uma festa/festival; habitualmente sacro-profana e, simultaneamente interativa de múltiplas funções econômicas e ecológicas, sempre capazes de se reinventar, como uma justificativa 
para "atrair" identidades novas e alteridades compatíveis com sua própria dimensão patrimonial. Talvez porque saiba mostrar que nenhum espaço excludente da metrópole, mesmo aquele com limitado potencial "festivo", deixe de potencializar essa atração aos lugares mais caóticos. Lugares que imitam os centros comerciais e zonas carnavalescas.

O eixo de nossa discussão é a reapresentação do simbólico metropolitano pela composição do espaço da festa, em sua capacidade turística de constituir-se patrimonial; e de ensinar, por mitificação contemporânea, que sua dimensão religiosa é dialógica, cosmopolita e pós-moderna. E se exercita pela ampliação da capacidade de envolver outros sujeitos (não-devotos) na festa, até compor o sentido coletivo de lugar. A metrópole do século XXI tem sido um espaço-cenário, um tempo mítico referencial e o modelo cibernético mais privilegiado para demonstração do poder das festividades. Demonstrar a festa como substrato simbólico-religioso é indispensável na criação do real. Somente há significação cultural, inclusive nos cultos à natureza, quando o festejar se projeta na escala das cidades-mães. Esta enfática sentença evidencia uma tese extremamente fechada e radical. Requer com isso o máximo de cuidado argumentativo e uma dose suficiente de paciência para não ser rejeitada de imediato. Que os próximos parágrafos deste ensaio possam responder pela ousadia de sua proposição.

\section{A FESTA RELIGIOSA COMO VEICULAÇÃO DOS SANTUÁRIOS RITUAIS}

Se para a Geografia da Religião a dinâmica devocional de participação em um rito religioso considerado em muitos casos como uma celebração festiva - pode ser interpretada no âmbito das representações simbólicas do sagrado (GIL FILHO, 2008, p.34), em uma abordagem educacional do patrimônio, uma festa religiosa sustenta-se mediante o fortalecimento de seu caráter mundano. Isto porque tal abordagem nos permite reconhecer a aproximação de suas dimensões comunicacionais, culturais (MATTERLART; NEVEU, 2004) e turísticas ((OLIVEIRA, 2007)), a medida que permitem a outras coletividades sentirem-se pertencentes à mesma festa. O sagrado como fenômeno intra-religioso, mantendo as leituras mais clássicas de E. Durkheim, R. Otto e M. Eliade (em especial), tende a conservar um jogo de complementaridade ou de oposição com as manifestações denominadas "profanas". Aquele conjunto de atividades percebidas pelo espectro religioso, que anuncia, prepara e conduz ao sagrado seja por atração ou repulsão, mas não se confunde com seu mistério inefável.

Neste jogo de aproximação, portanto, os arredores de um templo ou os momentos preliminares da festa de um santo padroeiro, podem ser reduzidos à condição de lócus profano. Exatamente por essa redução simplificadora, consideramos as premissas topológicas/cronológicas - cronotopos , conforme Bakthin - do modelo dual sagrado/profano insustentável, no contesto da festa metropolitana contemporânea. A multiplicidade de aspectos profanos do sagrado diversifica também o sagrado, aumentando a complexidade de quaisquer análises a respeito.

Por outro lado, é possível considerar uma perspectiva político-econômica da representação religiosa, quando lidamos com a leitura de autores comprometidos na interpretação da festa como um sistema simbólico (GERTZ, 1989) ou como uma estrutura renovável de controle e gestão da sociedade por intermédio da fé (BOURDIEU, 1998). Em qualquer uma dessas concepções se avança no sentido de interpretar o movimento de articulação dos sagrados e profanos das festividades, na compreensão da espacialidade religiosa. O que não significa dimensionar imediatamente a função simbólica dos rituais de celebração. Rituais que agem na convergência de imaginários e de múltiplas identidades para uma mesma festa religiosa. O dimensionamento é posterior; é construtor de uma sobre-realidade, algo racionalizado para além do dado (BACHELARD, 2003).

Nestes termos, que consideramos o festejar, em sua contextualização ambígua. Ambigüidade imanente e transcendente à religiosidade que lhe dá origem, correspondendo assim a uma ultrapassagem do simbolismo religioso imediato. A título de exemplo, uma festa como a do Pau da Bandeira de Santo Antônio, pode ser acolhida como festa ao santo padroeiro, aos ritos de fertilidade e a 
representação do município de Barbalha/CE no cenário da cultura regional/nacional. É possível compreender muitas festas como espelho identitário dos valores regionais que agregam ruralidades, padrões étnicos, tradições específicas, etc. (PAES; OLIVEIRA, 2010); no entanto, não é essa ampla tipologia de festividades que aqui tratamos com especial atenção. Tratamos das potencialidades simbólicas contemporâneas na festa auto identificada como religiosa, já que na maior parte das vezes seus valores identitários discriminam como "profanos" ou "invasores" toda uma lógica de inserção da apropriação popular (QUEIROZ, 1999). Daí considerar uma festa religiosa que vê as culturas urbano-metropolitanas como ameaça, torna-se, nesses termos, uma festa que "já não se vê", mas que precisa, necessariamente, de outros focos de interpretação.

Não é este o modelo das dinâmicas festivas que marcam os santuários católicos tradicionais brasileiros; estejam eles situados em famosos centros de peregrinação espalhados pelo país ou muitas vezes escondidos nas grandes e médias cidades brasileiras (OLIVEIRA, 2010). No momento em que a demarcação das festividades encontra nos centros urbanos as condições mais favoráveis de sua visibilidade e reprodução ampliada, novas tradições são rapidamente anexadas ao sistema de valores da própria comunidade (leia-se em seu espectro plural) responsável por gerir a festa como seu identificador cultural maior (CLAVAL, 1998; DURAND, 2008).

Vejamos dois exemplos bastante representativos de festa religiosa de santos padroeiros regionais; ambas marcadas por grandes romarias, nos Estados de Goiás e Ceará, nas cidades de Niquelândia (distrito de Muquém, zona rural na região centro-oeste) e Juazeiro do Norte (centro urbano de um pólo comercial e industrial nordestino). Trata-se notadamente de santuários da Igreja Católica, com forte tradição nas práticas peregrinas da religiosidade popular (ROSENDHAL, 1996) e toda combinação intercultural com as áreas rurais que marcam as respectivas devoções: a Nossa Senhora da Abadia do Muquém (no dia 15 de agosto) e a Nossa Senhora das Dores de Juazeiro do Norte (celebrada em 15 de setembro sobre a benção de Pe. Cícero, ícone religioso regional). A fim de subsidiar a dimensão festiva de ambos os santuários - patrimonializados pela própria Igreja Católica como a atribuição diocesana de Basílica Menor - tentaremos mostrar como ponto de partida do presente estudo a expressividade das mutações que as festas de padroeiro vêm incorporando. Dedicamos especial atenção às mutações que exigem o componente espetacular de sua programação. Utilizemos para tal demonstração os relatos noticiados pela mídia impressa regional, no intuito de chamar o leitor para importância da festa em um contexto de diversidade cultural e política que a realização da primeira e a programação da segunda vêm requerer.

O caso da Romaria das Dores, em setembro, fixada como uma das mais tradicionais do catolicismo popular nordestino incorpora-se, no ano de 2010, a uma festa cívico-religiosa. Afinal, o evento devocional marca simultaneamente a festa da padroeira da cidade fundada por Pe. Cícero e o reinício do ciclo das grandes romarias, a ser completado pelas romarias de Finados (novembro) das Candeias (fevereiro) de Aniversário do Falecimento de Padre Cícero (20 de julho).

O noticiário do Jornal O Povo, de Fortaleza-CE, edição de agosto de 2010, exemplifica-nos um modelo de divulgação que integra a tradição das grandes romarias com o projeto político de espetacularização dos cem anos de fundação da cidade-santuário de Juazeiro do Norte (Figura 1). Esse tipo de veiculação, que registra o fato e promove o evento, vem sendo uma das estratégias recorrentes de articulação entre as dimensões míticas e midiáticas de festas populares capazes de alçar a escala metropolitana.

Sobre a romaria de N. S. da Abadia, foram enfatizados os aspectos político-eleitorais capazes de transformar as melhorias de acesso (estrada, postos de atendimentos, reforma da Basílica com instalação de vaporizadores automáticos) em demonstração efetiva do poder das forças partidárias regionais. A devoção da padroeira do estado no povoado do Muquém (Niquelândia/GO) se traduz em uma festa cívica de indisfarçável matiz eleitoral. A religiosidade popular não esconde a ruralidade que a consolida; seja no percurso de peregrinos, no interior do templo e no imenso acampamento de devotos que permanecem 10 dias consecutivos como numa espécie de vigília coletiva 
pela Santa (BELLO, 1998). Porém os elementos da cultura urbana são emergentes em todas as frentes (sagradas, profanas e mundanas), ajustando a tradição do evento. Do lado institucional, o mais proeminente desses elementos é a parceria Igreja/Secretaria do Meio Ambiente/IBAMA. Um exercício de conciliação pioneiro e inesperado pelos rigores canônicos entre a ortodoxia católica e o a gestão do desenvolvimento sustentável.

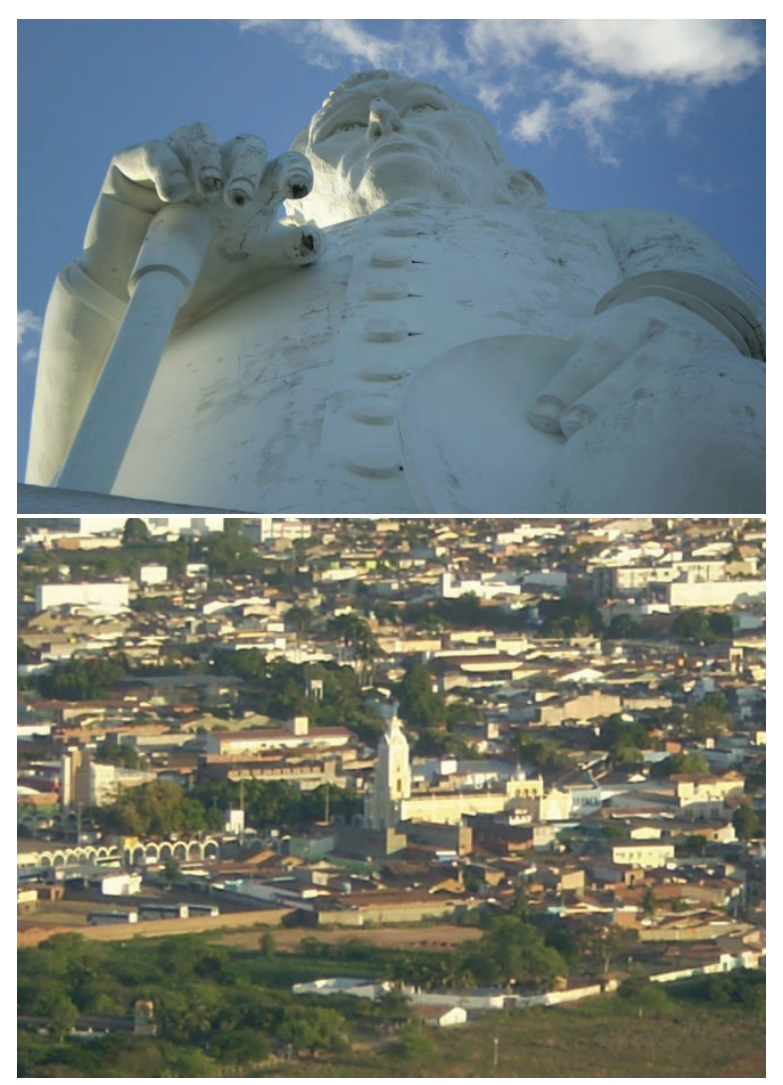

\begin{tabular}{l}
\hline Juazeiro do Norte \\
\hline Romaria reúne 400 mil devotos \\
\hline Todo setembro, N.S. das Dores recebe devoção e fé há \\
121 anos. as celebrações, que entram na programação \\
do centenário de Juazeiro do Norte, começam já neste \\
domingo, com carreata
\end{tabular}

Janaína Brás - Especial para O POVO 28/08/2010

Já se aproxima o mês em que Juazeiro do Norte completa 100 anos de emancipação política. As festas deste ano são as de número 99 desde o marco histórico da emancipação e preparam o terreno para as festividades de 2011. Com o tema "Juazeiro Centenário - Terra de Oração e Trabalho", a cidade se prepara para receber 400 mil romeiros de todo o Nordeste. A tradicional carreata de abertura das celebrações se realiza a partir das 8 horas deste domingo. Carros, bicicletas e motos enfeitados com capricho acompanham a imagem da Mãe das Dores saindo da Igreja Matriz e tomando conta das ruas da cidade de Juazeiro.

$\overline{\mathrm{A}}$ noite, serão hasteadas bandeiras dos estados nordestinos como reverência aos romeiros de outras localidades. Como marco de abertura, às 19h30min o padre Paulo Lemos Pereira preside a primeira missa da Festa da Padroeira. Daí em diante, são 17 dias de festa com direito a quermesses, procissões e missas diárias. Padres de todas as paróquias da cidade são convidados a presidir as celebrações na Basílica de Nossa Senhora das Dores. A devoção à Santíssima Virgem é inspiração de Padre Cícero, símbolo de Juazeiro e ele mesmo figura santificada pelos fiéis.

Figura 1 - Divulgação da Romaria da Mãe das Dores na imprensa regional

Fonte: http://opovo.uol.com.br/app/opovo/ceara/2010/08/28/noticiaceara,2035811/romaria-reune-400-mil-devotos. shtml, com fotos de Oliveira, 2009 - Estátua de Pe. Cícero e vista panorâmica do centro de Juazeiro do Norte.

As representações da devoção, na festa religiosa da padroeira (Figura 2), podem corresponder a uma sequência de ideias pré-concebidas capazes de veicular certa harmonia entre a iconografia da fé católica e vivência do romeiro. Entretanto essa "potencialidade" não nos auxiliaria na demarcação de característica latentes desses mesmos eventos hoje, seja como resistência socioambiental às mutações da modernidade; seja como expressões da mobilidade contemporânea, articuladas ao desenvolvimento de políticas para salvaguarda do Patrimônio Cultural Imaterial .

Em qualquer situação, entretanto, é possível capturar uma dinâmica de festas tradicionais em plena convergência e aproximação das marcas dos festivais da cultura urbano-industrial. E é neste movimento de modernidade - ora discreto, ora ostensivo - que um ícone do desenvolvimento ocidental ganha visibilidade inesgotável para pesquisas geográficas porvir: o carro como monumento alegórico. Um símbolo multiuso de transporte, comunicação e poder. Uma alegoria plena da expressiva carnavalização das festas populares. Nos exemplos tratados, as diversas máscaras de um deus automóvel - parodiando o clássico estudo de mitologia comparada de Joseph Campbell - faz evidenciar a força geográfica desse código do santuário ritual. Santuário marcado, simultaneamente, pelo tempo cíclico festivo e pelo lugar sempre instável, energético e alusivo à condição sacro-profana do festejar (SEABRA, 1996).

Daí não ser mais estranho ponderar um encontro da imaginação mítico-religiosa com o planejamento operacional dessas festas. Se na Romaria de N. S. das Dores, é possível constatar uma 
feira de automóveis sendo incluída na programação da novena; e se na peregrinação a N. S. da Abadia do Muquém, os automóveis absorvem papéis tão diversos do cotidiano - sendo utilizados como barracas, eletrodomésticos, depósitos e capelas - nada mais justo do que perguntar: é possível compor uma geografia dos santuários rituais, na contemporaneidade, ignorando a simbologia etnográfica do automóvel? Como reconhecer nas cidades e metrópoles brasileiras um "retorno do sagrado" sem a participação direta de veículos tão profanos? E no limite considerar: é possível crer se não sobre rodas?

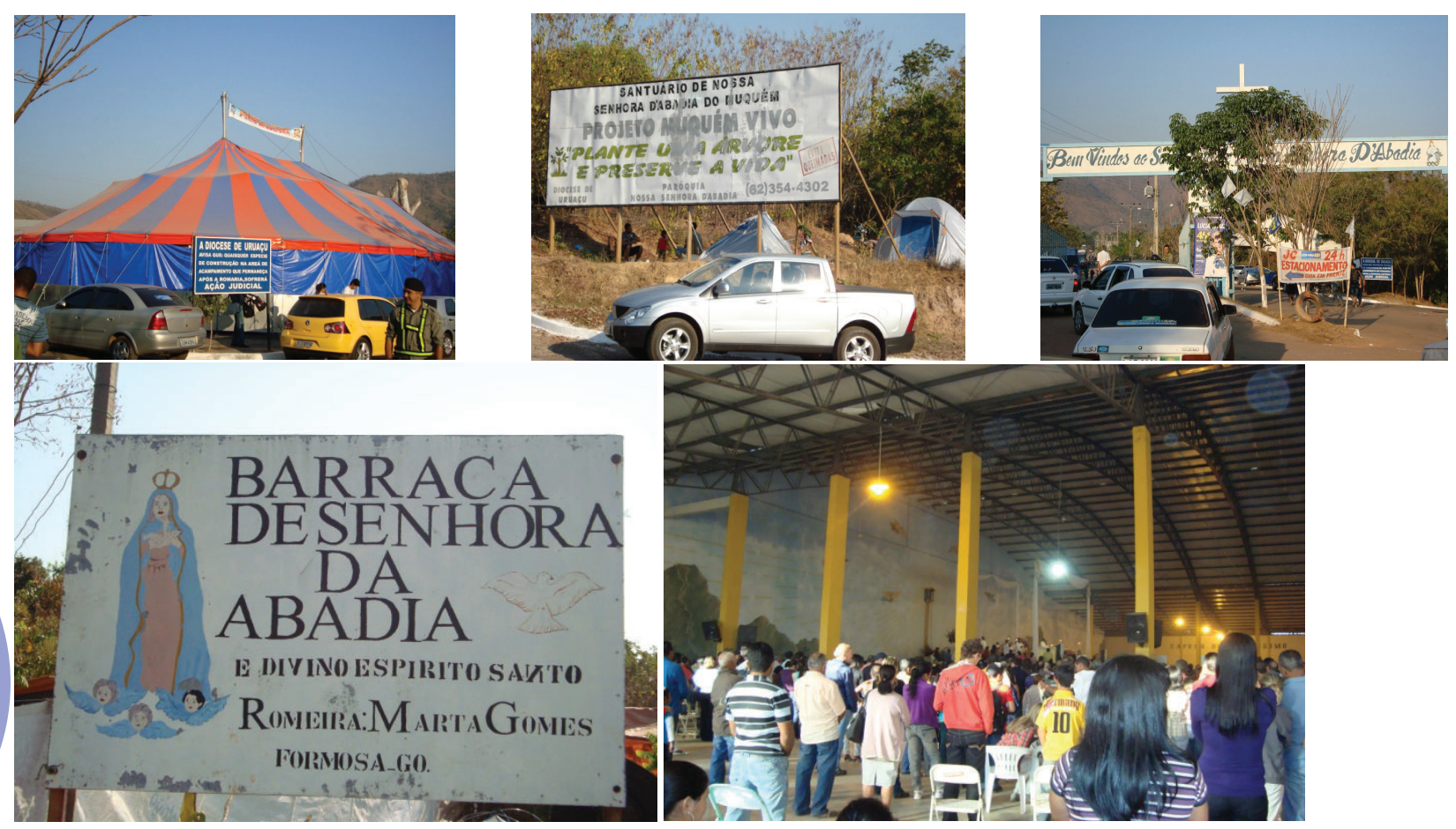

Figura 2 - Imagens da Romaria do Muquém-GO

Fonte: Seleção de fotos de Oliveira (2010) mostrando acampamentos e faixas indicativas dos arredores da basílica de Nossa Senhora da Abadia

A fluência da fé, no acesso, mesmo desigual (seja com paus-de-arara, seja por helicópteros!), aos centros de peregrinação, levou-nos a pensar a dinâmica dos santuários rituais como uma forma motorizada de expansão da lógica metropolitana. Regis Debray (2004) nos auxilia na interpretação direta de que a força religiosa da expansão judaico-cristã vincula-se imediatamente ao exercício técnico dos êxodos, diásporas e migrações. A religião do livro (o sistema judaico-cristão) é notadamente também uma religião da roda (reconhecendo sua tradição pastoril no deserto e sua diáspora ocidental). E, neste sentido, antes de discutirmos os vetores que motorizam e dão fluência a essas festivas localidades (santuários mundanos), podemos reconhecê-las em consistente encontro das tradições com a hiper-modernidade.

Exemplos cristalinos do processo transparecem nos andores-altares cada vez mais carnavalescos dos trios elétricos em procissões, nas carreatas de devotos e nas cavalgadas hodiernas motos-romaria! Encontro consistente, porém inusitado. Afinal causaria menos surpresa esperar esse comportamento devocional nas avenidas de São Paulo, Rio de Janeiro ou Fortaleza e justificá-lo por sua fragilidade nas condições de preservação das tradições da festa. Mas quando os ambientes interioranos de Juazeiro do Norte-CE e Muquém de Niquelandia-GO sugerem apropriar-se do automóvel com esse refinamento, o conhecimento científico da espacialidade dos rituais necessita lidar com outros parâmetros de compreensão. 


\section{VETORES PATRIMONIAIS DINAMIZAM LUGARES SIMBÓLICOS}

Os lugares simbólicos fazem convergir fatores culturais e ambientais diversos. Simbolizam, portanto, a partir do espectro da identidade religiosa, uma profusão de alteridades. Aqui reconhecidas como dimensões mundanas articuladas, que nos permite, pela prática moderna da visitação (seja turística, devocional ou acadêmica), constituir enquanto uma tipologia-modelo em quatro formas simbólicas de santuários.

São eles apresentados pelos seguintes nomes: Natural (predominantemente "pagão" e forte apelo contemporâneo no processo de valorização das áreas de patrimônio ambiental); Tradicional (predominante eclesial e enraizado nas marcas e marcos do catolicismo popular); Metropolitano (predominantemente empresarial produzido para expandir na lógica da modernidade e da diversidade cultural); e Ritual (simultaneamente capaz de realizar-se nos três e desaparecer como santuário, mediante sua condição de imaterialidade). Exploramos esses modelos mais detalhadamente em diferentes trabalhos anteriores (Figura 3). Associados preliminarmente aos 4 elementos da poética bachelardiana: Água/Vida, Terra, Ar e Fogo (FELICIO,1994).

Considerávamos, na elaboração da tabela-resumo (Tabela 1), uma dada hierarquia como partida para a observação das possibilidades de intercâmbio entre práticas devocionais de cada um deles, frente à matriz cristã católica, com a qual lidamos. Tal matriz acaba sendo desafiadora - quando não, um obstáculo - ao ignorar os vínculos as festas de padroeiros (fogo) em comunicação de original com práticas e ritos nos santuários naturais (água/vida).

Tabela 1 - Tabela-resumo das características que modelam os Santuários Turísticos

\begin{tabular}{c|l|c}
\hline MODELOS DE & \multicolumn{1}{c|}{ ESPAÇOS } & CORRESPONDENTES \\
SANTUÁRIOS & Peregrinações, procissões, festivais temáticos e rituais sacro-profanos & TURÍSTICO \\
FESTIVO/RITUAL & $\begin{array}{l}\text { Cidades com significativa diversidade de funções e representativa polaridade } \\
\text { regional }\end{array}$ & Emissivo/Atrativo/Acesso \\
\hline METROPOLITANO & $\begin{array}{l}\text { Lugares de devocionais que mantiveram a função religiosa em meio à } \\
\text { paisagem rural }\end{array}$ & Emissivo \\
\hline TRADICIONAL/RURAL & $\begin{array}{l}\text { Espaços representativos (muitas vezes protegidos) de um ecossistema dado, } \\
\text { apelo estético paisagístico e ocupação ritual pré-cristã. }\end{array}$ & Atrativo \\
\hline NATURAL & &
\end{tabular}

Fonte: Elaborado por Oliveira (2011)

Entretanto, algumas evidências contemporâneas alimentadas pelo avanço das questões ambientalistas modificam rapidamente aquela percepção de vínculo indireto. É possível compreender inclusive o peso do catolicismo mariano e as devoções a Nossa Senhora - tradicional ou renovada, conforme estudos de Steil, Mariz, Reesink, (2005) - como um forte indicativo da valorização simbólica da natureza (MERLEAU-PONTY, 2002). A partir dessa premissa, é possível reinterpretar que festas religiosas massivas, exatamente pelo predomínio da "divindade" feminina cristã, tornam-se celebrações a mãe-natureza, sem precisar abdicar das marcas tradicionalistas. E, conforme veremos na exposição dos gráficos mais adiante, associam por hibridação as festas ao compromisso patrimonial com os santuários naturais.

Porém, na expansão da "tendência ecológica" das festas religiosas, aproximando dois santuários aparentemente opostos, que forças seriam decisivas?

As pesquisas que vínhamos realizando, na interpretação geográfica do turismo religioso (OLIVEIRA 2004), e que nos propiciou chegar a esses modelos de santuários, absorveram o reconhecimento de que a perspectiva patrimonial - ou seja, a meta de uma valorização seletiva e diversificada do espaço geográfico - deva estar direcionada à formação educativa plena das sociedades contemporâneas. Em palavras mais diretas, entende-se agora que os lugares simbólicos têm função educativa explicita. E é exatamente a produção vetorial desse simbolismo que torna a 
questão patrimonial decisiva para interpretação da trama de intencionalidades sociais no espaço. Visualiza-se, portanto, uma geografia das representações como estratégia geopolítica no lugar simbólico. Veremos as características associativas dos vetores em questão, a partir do Diagrama da Articulação dos Vetores aos Santuários, apresentado a seguir.

Consideramos a mitologia, a política e a tecnologia contemporâneas, como forças motrizes e imaginárias na reorganização patrimonial dos lugares (PITTA, 2005). Suas particularidades permitiam projetá-los como representação da totalidade (da Terra, do Mundo ou do Universo), a partir da valorização integrada de seus princípios elementares: materiais e/ou etéreos. Um lugar simbólico é, paradoxalmente, um lugar incomum (excepcional), muito embora, na ausência de perspectiva patrimonial ou pelo destaque de apenas uma das forças motrizes, tal excepcionalidade permaneça camuflada; o que aumenta o papel do tempo sagrado (festa sacro-profana) como único portal à sua revelação.

Como tais forças atuam de maneira associativa - exatamente por buscar significações em uma sociedade multicultural e contemporânea - demarcamos um primeiro vetor, chamado de Mítico-Religioso, como a força que responde pela tradição cultural, do lugar e da festa. Neste sentido é o vetor de base, o primordial. Inúmeras vezes ele pode ser confundido, pelos estudiosos, como a única força que pode autenticar a identidade verídica do lugar simbólico como santuário da comunidade humana (local ou global). E não é para menos; o mítico religioso é o vetor de mais forte carga irracional (TERRIN, 1996). É aquele que contém os fundamentos de que qualquer processo educativo, precisa garantir hierarquias e saberes; e só depois, cumprir papéis acadêmicos, com métodos e técnicas embasados pela teoria. As religiões institucionalizadas - e particularmente o catolicismo-cristão em nosso caso - herdam isso e, de vez em quando, dinamizam santuários pelos caminhos exclusivos da tradição. O que é cada vez mais oneroso e conflituoso.

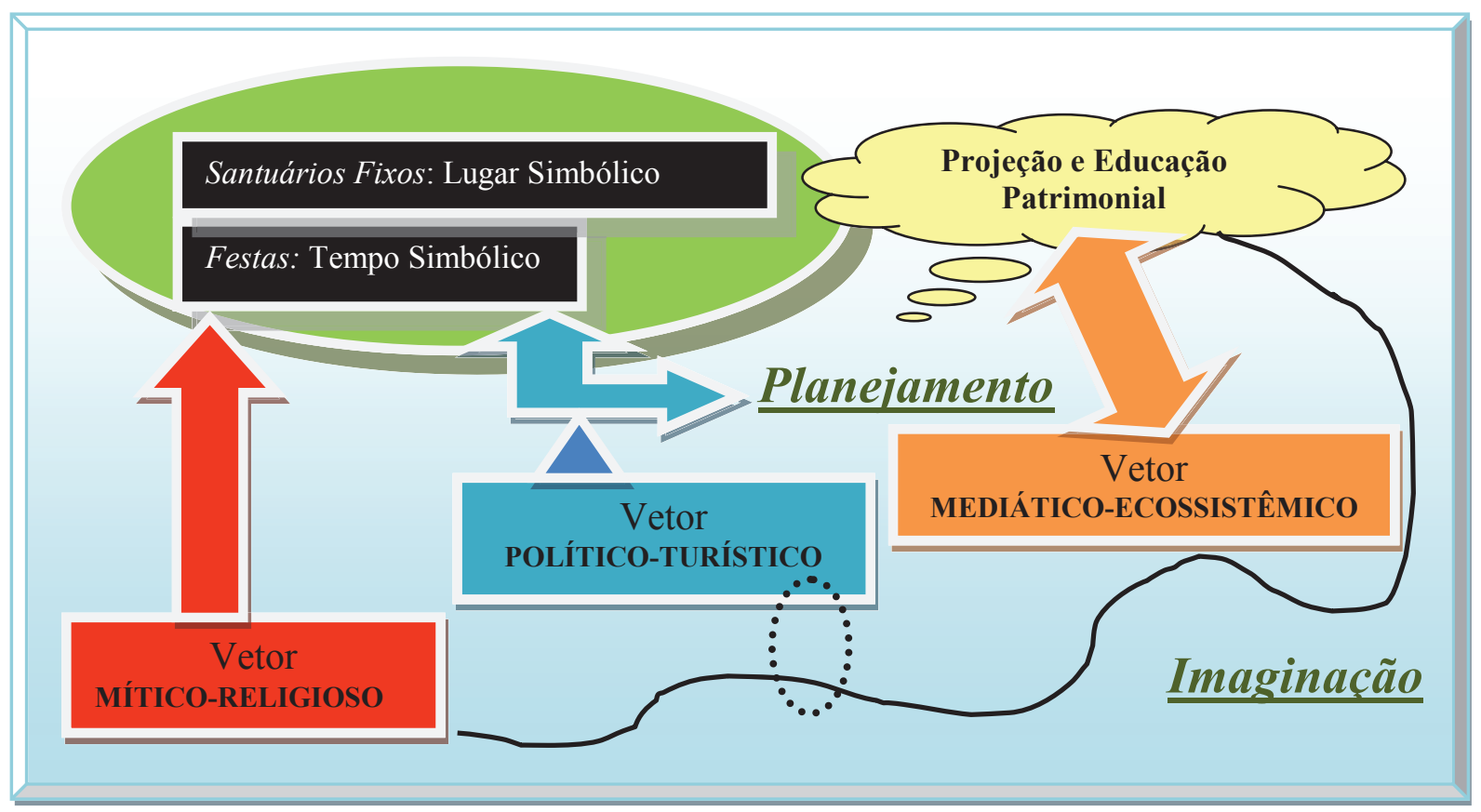

Figura 3 - Diagrama da Articulação dos Vetores aos Santuários Fonte: Elaborado por Oliveira (2011)

Daí o avanço sistemático para a associação com os demais vetores. O segundo, chamado de Político-Turístico, retrata o papel da gestão pública institucional da modernidade (MOESCH, 2000). Traz a racionalidade da experiência ocidental, na condução dos direitos humanos e civis sob a égide do Estado-Nação, pós-iluminismo, e na organização de uma territorialidade cada vez mais capitalista e urbanizada. O que permite - quando não exige - a transformação dos diversos nomadismos 
humanos em uma regulação mais flexível e positiva, como a que está representada pela visitação turística (BURNS, 2002; OLIVEIRA, 2005). A mesma que auxilia as redes de intercâmbio das diversas territorialidades em uma nova identidade. É do vetor político que emerge a constituição das GNPs (global networks parks), como a que envolve os Geoparques da UNESCO. E mesmo em escala Nacional, a partir da Lei $n^{\circ} 9.985$ de 18 de julho de 2000 que cria o Sistema Nacional de Unidades de Conservação (SNUC), esse processo evidencia crescentemente a preocupação com a gestão pública dos lugares simbólicos em rede. Voltaremos adiante ao assunto.

Além do papel político, e associadamente turístico, esse vetor pode ser considerado como o principal demandante do planejamento territorial dos lugares simbólicos. E por essa razão, a festa religiosa, com sua diversidade cultural, torna-se central na gestão dos processos de salvaguarda e proteção. Contudo, as bases legais de um Estado laico, mas crescentemente aberto às reivindicações de outras matrizes religiosas (principalmente Evangélicas e Africanas), deixa o vetor com permanente dificuldade de interação direta com o Mítico-Religioso. O que o obriga a delegar funções estratégicas na esfera mercadológica e promocional do vetor seguinte.

Por seu turno, o Vetor Mediático-Ecossistêmico, no sentido de promoção da sustentação econômica e ecológica simultaneamente, explora os avanços dos sistemas técnicos de uma automação pós-industrial. E por seu ritmo sempre acessível ao pragmatismo das imagens, que os veículos de comunicação e transporte fazem proliferar; pode-se nele reconhecer um alto poder de discriminação e efetivação dos lugares efetivamente simbólicos (FERRARA, 2008). Neste caso, não se trata de um reconhecimento institucional, fundado na lógica dos direitos jurídicos que aguarda a oficialização para exercer valor patrimonial. O vetor mediático-ecossistêmico - que também pode ser denominado mediático-sustentável - é aquele que mais rapidamente gesta, pelo controle das informações, uma economia dos bens simbólicos.

Por essa razão, nas festas em que fé e lazer (distanciados), ignoram as necessidades contemporâneas, o Vetor Mediático força a comunicação direta entre o simbólico de ambos até expor sua potencialidade patrimonial. Eis o motivo pelo qual posicionamos, no Diagrama, o Vetor Mediático com seta bidirecional interligada à "nuvem" patrimonial. Sua capacidade de planejamento e imaginação é praticamente instantânea, pois fé e lazer formam imediata identidade entre valores de uso e consumo. O "patrimônio" do vetor mediático é cria legítima da imaginação; ele precisa sim absorver as práticas institucionais do planejamento, advindas de uma cidadania (tão estatal quanto eclesial), mas não pode ignorar a inversão dos processos de valorização. Estes cada vez menos dependentes da materialidade orgânica dos monumentos (naturais ou culturais) são cada vez mais associados ao culto mediático dos espetáculos.

Assim é possível compreender a imaterialidade do patrimônio como meio de valorização dos bens tangíveis (monumentos, construções históricas, ecossistemas específicos) e dos processos educativo correspondentes. São as festas, as práticas comunitárias e os saberes que sustentam os simbolismos locais. Pensar o contrário tende a ser uma comodidade sim; mas não auxilia nem na explicação da explosão patrimonial hodierna e muito menos na percepção das articulações vetoriais responsáveis pela complexidade cultural que reponde pela necessidade de fazer com que todo santuário se torne um espaço turístico.

Desta feita, é possível lidar com o vetor político-turístico como um campo de mediações e negociações entre o vetor mais tradicional (mítico-religioso) e o mais tecnológico (mediático-sustentável). Isso porque o segundo vetor, embora vincule os requisitos legais da instituição pública do patrimônio, caracteriza-se pelo exercício metódico da própria ciência em busca de uma compreensão sempre "aproximativa" da realidade. Exerce, portanto, o cuidado epistemológico requisitado por Gaston Bachelard (2003), para lembrar que a ação científica, pode (quando não, deve) criar a realidade nova, exatamente por jamais ter acesso pleno à compreensão do mundo. Neste sentido, a prática científica, sem perder sua natureza política, encontra poder e competência no exercício turístico da visitação e funda uma metodologia para lidar com desafios típicos dos outros vetores. 


\section{OS SANTUÁRIOS (TRADICIONAIS) EM RELAÇÃO ȦS UNIDADES DE CONSERVAÇÃO}

Podemos afirmar que os santuários tradicionais do mundo católico possuem no vetor mítico-religioso um reconhecimento direto. Por consequência, pode-se dizer que grande parte da análise sobre a festa religiosa - em sua tradição geográfico-devocional - passa pela caracterização sistemática do fenômeno das romarias.

Também é possível desenhar a amplitude nacional desses santuários, tendo em vista os dados fornecidos pelo Anuário Católico 2009/2010, no que concerne ao Turismo Religioso. No total de santuários cadastrados (261) com reconhecimento das dioceses (nas 17 regiões episcopais do país), temos uma distribuição muito desigual deste modelo de lugar simbólico. Incluem-se, nessa mesma titulação, os centros regionais e nacionais de romaria e as igrejas que adquiriram esse título apenas por uma conjugação de fatores históricos e/ou eclesiais.
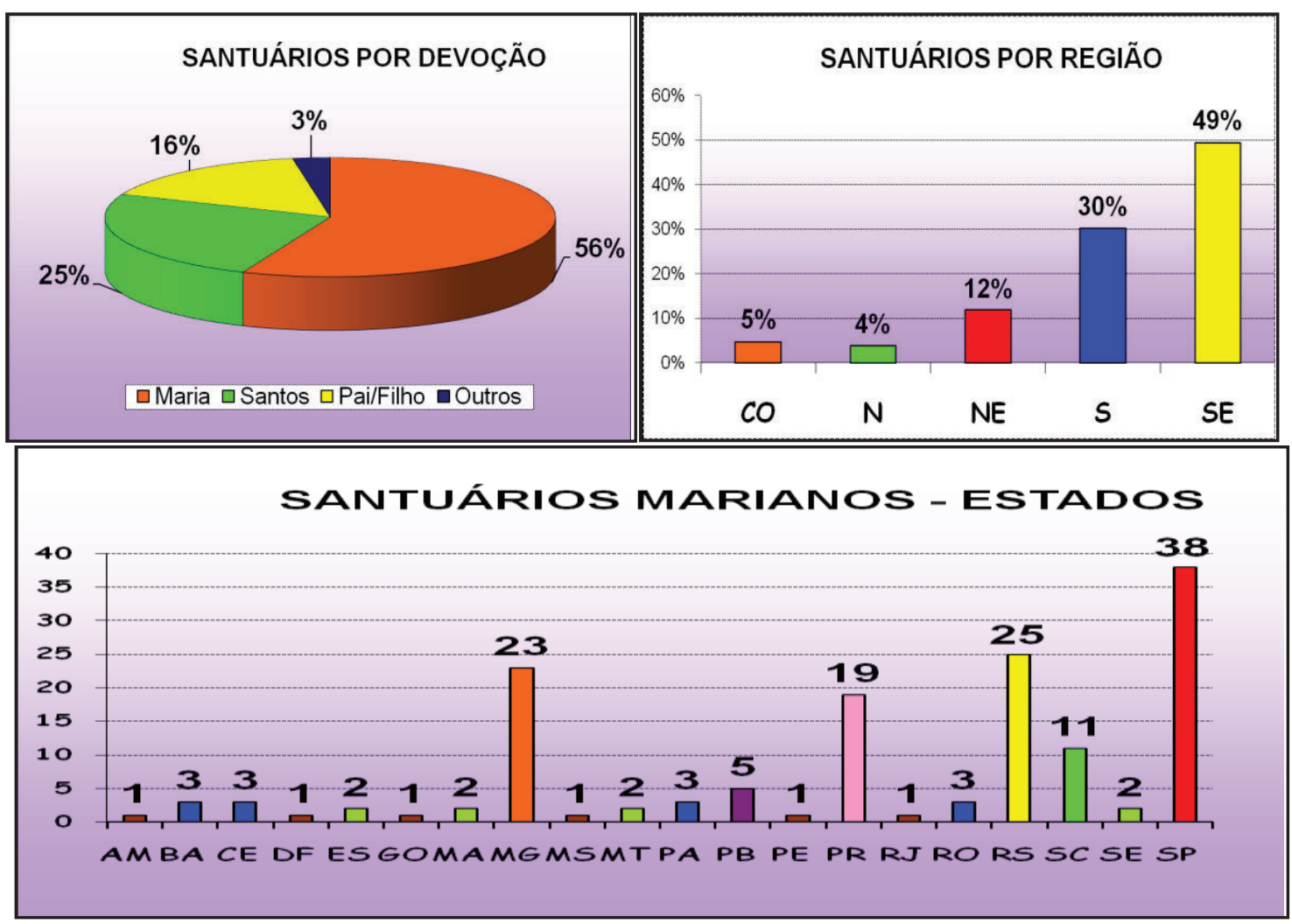

Figura 4 - Dados relativos aos Santuários Tradicionais.

Fonte: Oliveira (2010), a partir de dados disponíveis no Anuário Católico 2009/2010.

No agrupamento dos dados, constatamos uma concentração de santuários tradicionais marianos, por exemplo, em cinco estados da Federação: São Paulo (38), Rio Grande do Sul (25), Minas Gerais (23), Paraná (19) Santa Catarina (11), totalizando 116 do total de 147 santuários que têm Nossa Senhora como padroeira. Totalizam 5/4 dessa devoção tão relevante na atualidade. E mesmo no quadro geral (conforme gráficos da Figura 3) percebe-se que 79\% de todos os santuários situam-se no Sul e sudeste do Brasil.

Pode-se depreender desse fato que a forte religiosidade tão marcante nas regiões sertanejas e ribeirinhas do norte e nordeste brasileiro, bem como na expressividade católica do estado do Rio de Janeiro, não são representativas na distribuição dos santuários oficiais. Tais áreas muitas vezes lembradas como tipicamente brasileiras mostram-se até "tímidas" na diversificação de centros de peregrinação. Cidades-capitais como Curitiba e Porto Alegre com mais de 10 santuários cada, demonstram a força de um catolicismo institucional que não deixa de ser popular e muito menos 
reflui diante do crescimento de outros lugares simbólicos de matriz não católica. Ao contrário do Rio de Janeiro que oficialmente só indica ter um único santuário oficial.

Tais informações não impedem a avaliação de santuários "populares" que mesmo sem a titulação diocesana, comportam-se como centros consolidados de peregrinação. Entretanto, no que diz respeito ao foco de nossa reflexão - a transformação da festa religiosa, constituída na rede metropolitana, em valor patrimonial contemporâneo - temos uma clara limitação para compreender as celebrações festivas desses santuários sem indagar sobre a trama dos vetores em sua articulação simbólica. Afinal, são estados com redes urbanas expressivas e fortes níveis de industrialização. Aspectos que teoricamente dispensariam a necessidade de instalação de "tantos" santuários diocesanos. Em que medida não seria exatamente essa "ausência de necessidade" que torna a festa religiosa um bem disponível às novas necessidades hiper-modernas?

A questão pode se definitivamente ignorada quando passamos a observar a distribuição do que compreendemos por lócus privilegiado dos santuários naturais. São áreas reconhecidas pela concepção de unidades de conservação, via Ministério do Meio Ambiente, e sob a responsabilidade direta (desde 2007) do Instituto Chico Mendes. Mas essa possibilidade, entendemos, seria apenas uma leitura a partir das aparências, que ignora sim a história de consolidação dos processos. (ESTEVES, 2006). Inegavelmente a instituição de santuários católicos, segue uma lógica geográfica tradicional (do centro para a periferia). Já a política ambiental de um Sistema Nacional de Unidades de Conservação absorve um processo de direcionamento oposto, em sintonia com grandes conferências internacionais sobre meio ambiente. A demarcação dessas áreas desenhou, no país, uma distribuição regional e territorial muito mais equitativa para os santuários naturais. Expressão vigorosa de uma patrimonialização da natureza (LUCCHIARI; BRUHNS; SERRANO, 2007)

A distribuição das implantações, ao longo das três últimas décadas, demonstra o exercício de patrimonialização dos bens naturais como, prioritários, para regiões menos ocupadas pela concentração demográfica. Estes vêm sendo geridos da periferia para o centro, mostrando presença em estados amazônicos, nordestinos e no centro sul, sem grandes proporções tão concentradas territorialmente (Figura 5). Os estados da Bahia, Minas Gerais, Amazonas e Piauí se destacam; porém, entre os 67 parques nacionais brasileiros, não se pode afirmar um desequilíbrio proporcional a presença urbano industrial.

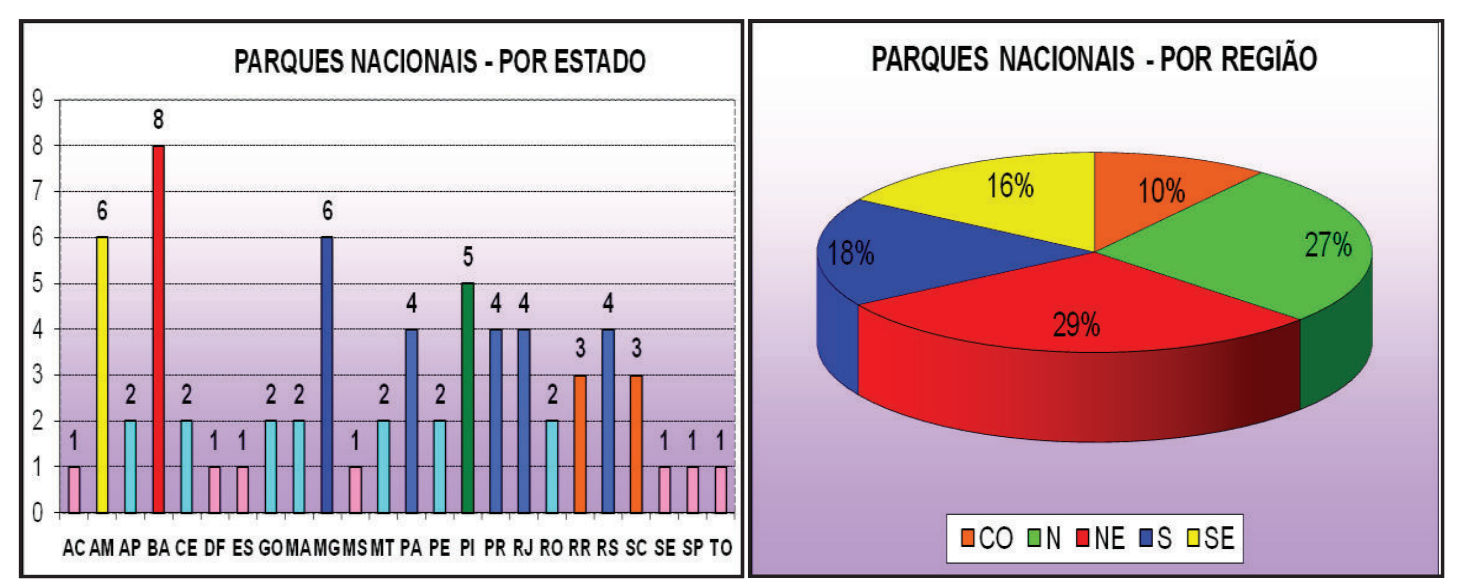

Figura 5 - Dados relativos aos Parques, como exemplos de Santuários Naturais, distribuídos conforme estados da federação e macro-regiões do Instituto Brasileiro de Geografia e Estatística.

Fonte: Organizado com dados do Instituto Chico Mendes de Conservação e Biodiversidade, disponível em http:// www.icmbio.gov.br/menu/instituicao

Muito embora, a discriminação de uso efetivo dos parques - que denota a real condição de seu manejo e gestão - chame atenção para um dado publicado até o mês de setembro de 2010, apenas 21 desses 67 parques estão abertos a visitação turística. Nessa proporção, a condição periférica em 
relação aos principais centros urbanos, pesa de maneira desfavorável para a maioria dos 46 parques não acessíveis atualmente.

Exposto assim pode-se depreender um fato imediato e uma tendência capaz de justificar a exposição desses dados, aparentemente tão díspares quando se trata de pensar festas religiosas e uma metodologia para sua investigação. $\mathrm{O}$ fato é que a dinâmica das festas de padroeiro, observada apenas no plano tradicional de sua realização, continua sem qualquer vínculo estético-ambiental motivador. A não ser que adentramos, caso a caso, em um nível de estudo das localidades que contextualizam tais santuários católicos para observar os diferentes níveis de gestão ambiental, não exatamente como parques nacionais. Neste caso, teríamos uma motivação para uma investigação sobre a dinâmica regional da festa e as suas práticas readaptadas pelas crescentes normativas territoriais conservacionistas.

Quanto à tendência aqui sugerida, a tese é de que a expressiva e crescente devoção à Nossa Senhora passa necessariamente por uma comunicação imaginativa, de características sacro-profanas, onde o culto católico atualizado encontre ressonância nas formas de sagração às forças da natureza. Sejam as que por ameaça de extinção precisam de manifestações sociais em alerta; sejam aquelas compreendidas na lógica das grandes catástrofes reagentes. São simbolicamente as formas de comunicação da mãe-terra (NEUMANN,1996). Quando estas podem ser revestidas pela divindade católica modelar - Maria, mãe de Deus - dá-se uma confluência interessante. É verdade que territorialmente os dados aqui apresentados não fazem coincidir os mesmos padrões de santuários. Mas quando observamos as tendências e preocupações dos santuários rituais com a sustentabilidade, segurança e bem-estar geral, temos de voltar nossa atenção para os limites diretos (e até internos) das unidades de conservação, no sentido de indagar: em que medida as pequenas festas de padroeiros, das comunidades vizinhas a essas unidades são os principais gestores coletivos da proteção a tais unidades? E, em sentido oposto, até que ponto, a falta dessa festa religiosa e/ou desse santuário ritual ajuda a explicar o relativo abandono daquele Parque Nacional?

São questões relativamente estranhas, mas que esboçam um caminho metodológico para o desenvolvimento de investigações mais articuladas entre os Santuários Naturais e as práticas rituais da religiosidade popular. Afinal, antes de afirmar a compreensão pela necessidade de conservação da natureza, as comunidades tendem a afirmar sua crença. Nas raízes culturais brasileiras, compreender sem acreditar é quase uma irracionalidade.

\section{CONSIDERAÇÕES FINAIS}

Quando Sabáh Aoun (1997) diagnosticava no imaginário e no empreendimento global do turismo contemporâneo, um processo de imitação - reprodução de um simulacro - deturpadora da cosmogonia judaico-cristã, não considerava em suas reflexões uma possibilidade inversa. Quais as vantagens religiosas de uma catequese cristã em projetar, no imaginário do devoto, um passaporte para as mais belas obras de Deus na Terra? Caberia pensar o quanto a explosão cibernética de "imagens do paraíso" facilita significativamente a expansão e diversificação da religiosidade contemporânea? Assim como estimular as diversas forma de celebrá-la?

Entendemos, para efeito de encerramento desde ensaio, pautados pela articulação ritual de dois modelos de santuários, que sim: o cristianismo católico dá sinais evidentes de que passou a exercer festivamente uma aclamação divina ao paraíso terrestre. Mesmo que isso não possa ser absorvido na esfera dogmática como fim ou alvo principal da teologia cristã, a mediação e a energia educacional, que as imagens da natureza emanam, vem se transformando em códigos evangelizadores. É essa a tese que aventamos quanto tentamos articular o crescente número de santuários marianos com a necessidade dos parques e áreas protegidas "reconverterem-se" em paraísos telúricos.

Que passos metodológicos poderiam, a partir dessa inversão, subsidiar estudos a respeito dos Santuários Naturais, crescentemente abertos para a festa religiosa? 
Pensamos, para efeito de discussão, ser aquele que possa ser reorientado na investigação empírica sobre a natureza patrimonial de "lugares da natureza", enquanto cenário de revelação de uma espacialidade simbólica. É mediante a comunicabilidade dessa natureza-jardim-paraíso (AOUN, 1997) com a religiosidade tradicional (cada vez mais renovada, diga-se de passagem), que os santuários rituais das festas religiosas avançam na lógica patrimonial. Cumpre, portanto, a uma geografia das representações simbólicas:

. Mapear e analisar as formas vivas da religiosidade presente (interna ou vizinha) à aquele santuário natural específico, a fim de ponderar o quanto essa presença veicula as práticas conservacionistas do lugar. Portanto, desenhar a atualização da religiosidade como prática de reaprendizagem no convívio com o ambiente natural.

. Interpretar o processo dessas mesmas práticas como epicentro, local e temporal, de valores patrimoniais integrados, em alguma rede cultural e originados, em função de lugares (também simbólicos, muitas vezes) demandantes da festa religiosa, ou seja, incluir na interpretação da festa, a carga regional metropolitana que costuma atualizar sua demanda contemporânea.

- Avaliar, com elementos cientificamente mais criativos, as associações desses rituais festivos com a valorização do arquétipo feminino; reunido no imaginário geográfico dos símbolos Mãe $\Leftrightarrow$ Mulher $\Leftrightarrow$ Deusa $\Leftrightarrow$ Maria/N.Senhora $\Leftrightarrow$ Natureza $\Leftrightarrow$ Terra. Com isso, aproximar ou afastar, conforme a avaliação, as codificações que permitiriam dimensionar até onde esta é uma nova questão de gênero, mais pragmática ou mais ontológica.

. Promover a decodificação dos vetores, no intuito de responder, mesmo em nível parcial: uma educação patrimonial, demanda de fato, o festejar religioso em santuários naturais?

São estes nossos passos experimentais para um exercício metodológico de investigação sobre os lugares simbólicos, nos quais uma visão de natureza é ainda o centro do culto. E como todo centro pode polarizar muitas periferias, é a periférica festa religiosa que elegemos para investigá-lo.

\section{REFERÊNCIAS BIBLIOGRÁFICAS}

AOUN, Sabáh. Paraíso à Vista: Os Jardins do Éden Oferecidos pelo Turismo. In: RODRIGUES, Adyr A. B., Turismo e Espaço: Rumo a um conhecimento transdisciplinar. São Paulo: Hucitec, 1997

AVENS, Robert. Imaginação é Realidade. Petrópolis-RJ: Vozes, 1993.

BACHELARD, G. Ensaio sobre o conhecimento aproximado. São Paulo: Contraponto, 2003

BELLO, Ângela. Culturas e Religiões: Uma leitura fenomenológica. Bauru: Edusc, 1998.

BURNS, P. Turismo e Antropologia, uma introdução. São Paulo: Chronos, 2002.

BOURDIEU, P. O poder simbólico. Rio de Janeiro, Bertrand, 1998.

CAMPBELL, Joseph. A Extensão Interior do Espaço Exterior: A metáfora como Mito e Religião. Rio de Janeiro: Campus, 1998

CLAVAL, Paul. A geografia cultural. Florianópolis: Editora UESC,1999

COMPARATO, Doc. A Guerra das Imaginações. Lisboa: Pergaminho, 1998

CORREA; ROSENDHAL (Org). Geografia Cultural, um século (2). R. de Janeiro: Eduerj, 2002.

DARDEL, Eric. O Homem e a Terra, Natureza da Realidade Geográfica. São Paulo: Ed. Perspectiva, 2011.

DEBRAY, R. Deus um itinerário. São Paulo: Companhia das Letras, 2004

DURANT, Gilbert. Ciência do Homem e Tradição: o novo Espírito Antropológico. São Paulo, Trion. 2008.

ESTEVES, Caio M. P. Evolução da criação dos Parques Nacionais no Brasil. Monografia de Engenharia Florestal da UFRRJ - Orientação: José de Arimatéa Silva, 2006. Disponível em http://www.if.ufrrj.br/inst/ monografia/Monografia\%20Caio\%20Marcio\%20Proetti\%20Esteves.pdf 
FELÍCIO, V. L G. A imaginação simbólica nos 4 elementos Bachelardianos.São Paulo: EDUSP, 1994 FERRARA, Lucrécia D’A. Comunicação, Espaço, Cultura. São Paulo, AnnaBlume, 2008. FITORAMO G; PRAND, C. As ciências das religiões. São Paulo: Paulus, 1999

GERTZ, C. A interpretação das Culturas. Rio de Janeiro, Zahar, 1989.

GIL FILHO, S. F. Espaço Sagrado: Estudos em Geografia da Religião. Curitiba: Editora IBPEX, 2008. LUCCHIARI, Maria T. P.; BRUHNS, Heloisa T.; SERRANO, Célia. Patrimônio, Natureza e Cultura. Campinas: Papirus, 2007.

MATTERLART, A; NEVEU, E. Introdução aos Estudos Culturais. São Paulo: Parábola, 2004.

MERLEAU-PONTY, Maurice. A Natureza. São Paulo. Martins Fontes, 2000.

MOESCH, Marutschka. A produção do saber turístico. São Paulo: Contexto, 2000

NEUMANN, Erich. A Grande Mãe. São Paulo: Cultrix, 1996

OLIVEIRA, C. D. M. de. Turismo Religioso no Brasil: Construindo um investimento sócio-cultural. In: TRIGO, L. G. (Coord.). Turismo: Análises Regionais e Globais. São Paulo: Rocca, 2005, p.325-344

OLIVEIRA, C. D. M. de. Desafios Contemporâneos das Cidades-Santuários no estado do Ceará (Brasil): Políticas patrimoniais e diocesanas. Revista Geosaberes, V. 1, nº 1, 2010, p.37-51

OLIVEIRA, C.D.M. de. Festas Populares Religiosas e suas dinâmicas espaciais. Mercator, V 06, n 11 , 2007, p.23-32.

OLIVEIRA, C. D. M. de. Turismo Religioso. São Paulo: Aleph, 2004

PAES, Maria T.D; OLIVEIRA, Melissa R. da S.(Orgs.). Geografia, Turismo e Patrimônio Cultural. São Paulo: Fapesp, AnnaBlume, 2010.

PASTRO, C. Arte Sacra. O espaço sagrado hoje. São Paulo, Loyola, 1993.

PITTA, Danielle Perin Rocha (org). Ritmos do Imaginário. Ed. Universitária UFPE, 2005.

QUEIROZ, Maria Isaura. Pereira de. Carnaval Brasileiro o vivido e o mito. São Paulo: Brasiliense, 1999.

ROSENDHAL, Z. Espaço e Religião: Uma abordagem geográfica. Rio de Janeiro: EdUERJ, 1996.

SEABRA, Zelita. Tempo de Camélia: o espaço do mito. Rio de Janeiro: Ed.Record, 1996.

SILVA; GALEANO. Geografia: ciência do complexus. Porto Alegre, Ed. sulina, 2004

STEIL, Carlos A., MARIZ, Cecília. L, REESINK, Mísias L.(orgs). Maria entre os Vivos. Porto Alegre, Ed. UFRGS, 2003.

TERRIN, Aldo N. Nova Era: a Religiosidade do Pós-Moderno.São Paulo: Loyola, 1996.

Trabalho enviado em julho de 2011 Trabalho aceito em setembro de 2011 